\title{
High-Low as expression of the Brazilian digital fabrication
}

\section{SIGRADI2018 TECHNOPOLITICAS \\ xxii congresso da sociedade iberoamericana de gráfica digital 22th conference of the iberoamerican society of digital graphics 07|08|09|novembro|2018 iau usp | são carlos | sp br}

\author{
Arq. Daniel Locatelli \\ Atelier Marko Brajovic | Brazil | daniel.nlocatelli@gmail.com \\ Arq. Adalberto de Paula \\ Atelier Marko Brajovic | Brazil | depauladalberto@gmail.com \\ Me. Thiago Henrique Omena \\ Doutorando FAU USP | Brazil | thomena@gmail.com \\ Prof Dr. Arthur Lara \\ FAU USP | Brazil | arthurlara@usp.br
}

\begin{abstract}
This paper is the result of an investigation about the influence of digital processes in Design and its importance in innovation within ephemeral architecture through the concept of HighLow. The ephemeral architecture has the potential to combine academic and artistic knowledge to Brazilian commercial production. Here is presented one experimental case study designed to Expo Revestir for Docol in 2017 that balances the paradigm of computational design with the academic field and viable commercial applications.
\end{abstract}

Keywords: High-Low; File-to-Factory; Ephemeral Architecture; Computational Design;

\section{INTRODUÇÃO}

O modo de viver e de ocupar o mundo sofreu uma grande transformação ao longo da história com as inovações alinhadas à cultura local no mundo globalizado. Recentemente, após meados do século XX, a explosão populacional transformou o meio urbano com as novas tecnologias de produção para responder aos problemas emergentes. Como resultado um mundo globalizado repleto de inovações, os processos de projeto e a execução da arquitetura também podem ser citadas evoluções que ocorreram por meio das tecnologias disponíveis.

Como já propunha Rivka Oxman (2006) quando escreveu "Teoria e Design na primeira era digital" (tradução nossa), o processo de projeto clássico antes entendido como análise, síntese, avaliação e decisão; quando em um ambiente digitalmente mediado passa pelas fases de geração, representação, avaliação e desempenho. Essa mudança na mediação do projeto acontece após grandes transformações que ocorreram na fabricação com a introdução das máquinas numéricas que passariam a controlar toda a linha de produção das indústrias aeronáutica, naval e automobilística. No entanto, a expressão concreta dessas tecnologias, na arquitetura, acontece de acordo com a realidade política, social, econômica e cultural de cada região.

Desde a década de 1950, o computador auxilia na produção de peças complexas de aviões. Para Gabriela Carneiro (2014), o computador é como um parceiro do arquiteto na formulação e geração de espaços. "Mais do que a modelagem de formas, a partir de suas aparências, o foco do arquiteto foi sempre o de empregar, na arquitetura, a potencialidade do computador em simular processos naturais" (CARNEIRO, 2014, p.87). Responsáveis pela introdução da computação na prática arquitetônica, as primeiras gerações dos softwares computer aided design - CAD, usavam o ambiente digital como uma espécie de prancheta eletrônica (ao invés da utilização do computador como um assistente do processo criativo, ele era usado apenas como ferramenta de representação gráfica) como apontou Araújo (2018)

Para Sedrez (2018) antes da industrialização da construção, havia uma valorização das formas complexas quando os métodos artesanais eram condicionados à arquitetura; entretanto, no período pós-guerra, a fabricação da arquitetura sofreu grandes mudanças, e foi essa mudança que foi apontada como uma das bases do modernismo. Período este em que surgiram diretrizes ideológicas que defendiam as formas simples (em virtude da simplificação e rapidez na fabricação arquitetônica). Assim, esta foi uma condicionante que catalisou o desaparecimento das formas complexas, conforme apontou Sedrez (2018) ao afirmar que "outra questão a se considerar, no que diz respeito à simplificação das formas, são os meios de produção industrial do início do século $X X$, que estavam direcionados à produção em massa" (SEDREZ, 2018, p. 56).

Com a evolução dos computadores e a rapidez e aumento da capacidade no processamento de dados, o ambiente digital passou a auxiliar também os processos de projeto no que ficou conhecido como Digital Design. A defesa desta nova área de estudo ficou a cabo de expoentes como William Mitchell em seu manifesto antitectônico, Rivka e Robert Oxman, na defesa do novo Estruturalismo (que invertia a ordem do processo de 
projeto de forma, estrutura e material, para material, estruturação e forma), entre diversos outros autores de igual importância.

Nesta nova forma de pensar o processo de projeto digital, o computador além de produzir desenhos, era também utilizado na resolução de problemas lógicos ligados ao processo de design. Esses softwares que assistiam concepção arquitetônica abriram novas oportunidades por permitirem a produção e construção de formas complexas que eram, até pouco tempo atrás, difíceis e caras de serem projetadas, produzidas e montadas usando tecnologias tradicionais de construção. Passando pelas quatro revoluções industriais, a máquina a vapor, a produção em série, a customização em série com as máquinas $\mathrm{CNC}$ e a indústria 4.0, uma nova tradição foi estabelecida por meio das tecnologias digitais ao ligar diretamente o projeto ao canteiro de obra.

Antes do início da digitalização do processo criativo arquitetônico, a prática projetual era desenvolvida de forma a atender a fabricação manual e mecânica. Através do processo digital de projeto e da fabricação digital, aqui definida como a produção de objetos físicos a partir de modelos digitais (TRAMONTANO, 2016), a arquitetura ganhou uma camada híbrida de materialização que não precisa se render à infinita repetição para facilitar a produção. Assim, por meio desse processo, "adota-se a ideia de uma produção que trabalha com o arquivo digital do projeto sendo enviado e produzido diretamente na indústria, processo conhecido como file-to-factory" (TRAMONTANO; SOARES, 2012). Cada técnica artesanal antes feita por mãos, dentro dessa esfera, passa a ser repensada através de processadores e máquinas a fim de otimizar o processo de forma a ampliar suas possibilidades. Dessa maneira, a fabricação digital consegue atingir um nível extremamente alto de definição da forma, muito superior à capacidade humana quando falamos de geometrias complexas produzidas em série com precisão.

Por outro lado, a formação de um arquiteto no Brasil é muito abrangente, permitindo um grande leque de atuação. A construção civil, que é um dos seus principais focos, costuma ter longos prazos de execução e pouca abertura para exploração e experimentação de novas técnicas e métodos de design. No entanto, atualmente, "existe no Brasil uma lenta, mas irreversível alteração nos processos produtivos da construção advindo da ampliação dos processos industriais, agora potencializados pelo advento da informatização" (TRAMONTANO, 2016, p.01). A tecnologia sempre foi pensada de forma autônoma, isolada, como vanguarda de futuros e soluções evidentes para problemas que ainda não conhecemos. Assim, dentro desse cenário, a arquitetura efêmera consegue incluir métodos de projeto digitais por possuir, geralmente, peças únicas e com um nível de complexidade alto se comparado com a construção civil tradicional. Além disso, dentro dessa área os prazos de elaboração do projeto e construção, que variam de 1 a 6 meses, costumam ser mais baixos e com um alto orçamento. Em um projeto típico de arquitetura efêmera para eventos, a eficiência em todas as etapas de desenvolvimento gera uma pressão vinda desse curto prazo e de seu alto custo. Dessa maneira, essa área se mostra um campo naturalmente fértil para 0 desenvolvimento e utilização de métodos de projeto com o uso da fabricação digital.

Trazendo essa discussão para a prática profissional arquitetônica dentro da arquitetura efêmera, vamos usar como base de estudo o projeto da estrutura experimental desenvolvida na Expo Revestir para a Docol em 2017 pelo Atelier Marko Brajovic que equilibra o paradigma do design computacional com o campo acadêmico e aplicações comerciais viáveis. Dentro deste ateliê, o processo de concepção e produção dos projetos podem ser separados em três etapas principais: o conceito, a consolidação do conceito como anteprojeto e a fabricação com os arquivos necessários para materialização.

A fase de conceito, no qual são levadas em conta referências arquitetônicas, cenográficas e teóricas, não possui uma linearidade que possa ser descrita sistematicamente. O que ocorre são muitas iterações observando o feedback de cada resultado. Nesta etapa o projeto é pensado de maneira que sejam consideradas hierarquias de geometrias, ou seja, ele geralmente é desenvolvido por modelagem tradicional CAD, mas de forma que facilite futuramente que o projeto evolua para um sistema generativo.

\begin{abstract}
"Um sistema generativo (SG) é uma definição ou método de obtenção de uma solução para um dado problema com parâmetros em aberto, que permite a geração de múltiplas alternativas, a partir da entrada de valores para esses parâmetros. Os SG's podem ser formados, por exemplo, por conjuntos de regras que podem ser aplicadas em diferentes ordens e combinações ou por modelos geométricos paramétricos." (SEDREZ, apud CELANI, 2018 p.25).
\end{abstract}

Este tipo de abordagem evita a elaboração extremamente detalhada de um projeto que talvez não seja levado à diante. No entanto, ele já possui desde sua concepção uma racionalização de maneira que possa posteriormente, ser produzido através da fabricação digital. O arquiteto Marko Brajovic chama isso de "simular a parametrização". Porém, nem todos os projetos chegam a se tornar sistemas generativos, alguns atendem 0 conceito e programa de necessidades apenas com uma modelagem tradicional.

A segunda etapa é a de consolidação do conceito, conversão do projeto para o sistema generativo, e produção dos arquivos e desenhos necessários para a fabricação. Nesta fase o projeto avança também em sistema de feedback, mas as iterações são relativas ao programa de necessidades, dimensões disponíveis, compatibilização entre projeto elétrico, hidráulico e de iluminação. O uso de parâmetros variáveis é muito importante neste momento, pois evita a necessidade de remodelar o projeto a cada iteração, já que o modelo, arquivos e desenhos são atualizados automaticamente após cada modificação.

Na terceira etapa chega-se ao projeto executivo junto à fabricação. Dentro das diversas possibilidades de fabricação, duas formas costumam acontecer caso o projeto tenha chegado a usar um sistema generativo. Uma delas é a produção de componentes através da 
fabricação digital (FD) usando principalmente máquinas CNC. O outro modo de fabricação parte da geração automática de desenhos para, em seguida, serem encaminhadas para o fabricante que utilizará de meios comuns para o desenvolvimento do projeto. Quando é utilizado no projeto o segundo formato, acontece uma junção das novas tecnologias introduzidas no modo de fazer arquitetura com as técnicas tradicionais de construção. Essa união do que é tecnológico com o tradicional, alinhado com os materiais e cultural local, define o conceito de High-Low defendido por Anne Save de Beaurecueil (CELANI, SEDREZ, 2013), sócia fundadora do SUBdV, que tem potencial de agregar à arquitetura contemporânea brasileira características próprias locais em detrimento da arquitetura internacional.

\section{HIGH-LOW}

De acordo com o SUBdV (2017) o termo High-Low surge da união de dois conceitos, onde High representa a tecnologia utilizada para a geração da arquitetura através da computação e o Low as instruções produzidas para que uma mão de obra não especializada possa construir com fabricação digital. Por exemplo, em um de seus projetos, o CoBLOgó, foram exportadas guias de posicionamento das peças a partir de um script paramétrico. Estas guias foram cortadas a laser em material papelão e colocadas numa estante também fabricada digitalmente com a router CNC onde o mestrede-obras só precisou colocar os blocos adjacentes às guias e vergalhões intercalados para integridade estrutural. Em suma, este processo que une o design paramétrico e fabricação digital com técnicas simples de construção e materiais locais ao canteiro de obra ilustra o processo chamado High-low. (SUBdV, 2017) Esse artifício que combina alta tecnologia (computação paramétrica e fabricação digital) com métodos de construção de baixa tecnologia e materiais locais baratos, pode criar uma nova identidade brasileira ao design digital, para escapar à crescente tendência ubíqua e genérica da estética paramétrica contemporânea. (SUBdV apud ROJAS, 2017, Tradução nossa)

A partir do pensamento de Anne Save de Beaurecueil, a baixa quantidade de universidades que trabalham com fabricação digital e arquitetura paramétrica é um dos problemas na formação do arquiteto no Brasil que geram o atraso da industrialização da construção arquitetônica com precisão. "Se os arquitetos não estiverem usando técnicas novas eles não vão pressionar a indústria de construção para mudar. [...] então acho que, para realmente avançar na construção, é preciso começar com os alunos, pois eles irão pressionar a indústria, irão inspirar a indústria." (CELANI, SEDREZ, 2013). Assim, o High-low é uma maneira de inovar não apenas repetindo o que está acontecendo no cenário internacional, mas de unir a arquitetura e a cultura brasileira com a nova tecnologia que vem de fora.

\section{ESTUDO DE CASO: PAVILHÃO DA DOCOL 2017}

\section{PRIMEIRA ETAPA - PROJETO CONCEITO}

A primeira etapa foi a do projeto conceitual, na qual se estudou as novidades dos produtos da empresa e seu posicionamento no mercado. Foi assim que se chegou à ideia de relacionar a nova linha de torneiras com ozônio ao conceito a ser proposto. Quando o ozônio é misturado à água, ele a concede propriedades higiênicas, como combate à micro-organismos e remoção de cheiros fortes sem, no entanto, prejudicar o meio-ambiente. Foi então definido que a estrutura final do pavilhão da Docol deveria se remeter à molécula do ozônio, ou seja, três átomos de oxigênio conectados entre si. A forma final deveria então ser composta por três domos que se intersectam, a casca deveria utilizar policarbonato alveolar e os domos concebidos de forma a mimetizar um diagrama de voronoi, ou seja, as superfícies desses três domos deveriam ser "revestidas" com células de voronoi. O conceito é então resultado do diálogo entre uma ideia que se conecta com a marca e um sistema construtivo eficiente.

Este resultado foi alcançado seguindo um processo não linear de projeto que sofreu iterações até se chegar ao produto final. Ou seja, existiu um processo de estudo de várias condicionantes que foram aos poucos se conectando através do feedback de múltiplos testes intermediários. No Atelier Marko Brajovic entende-se que no processo de projeto "não importa mais se você

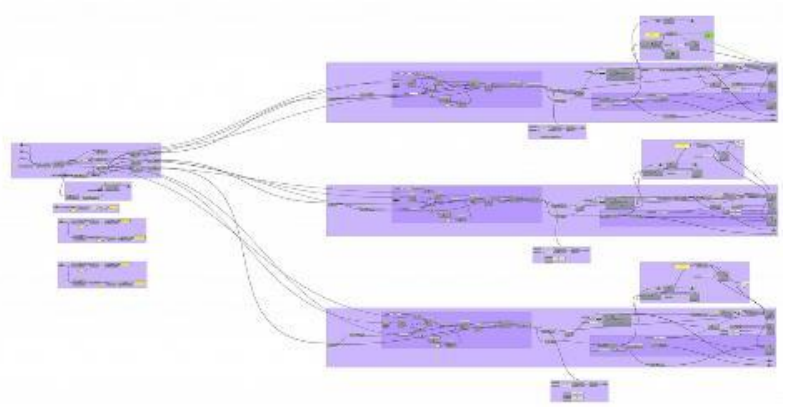

Figura 1: Algoritmo (Fonte: autores)

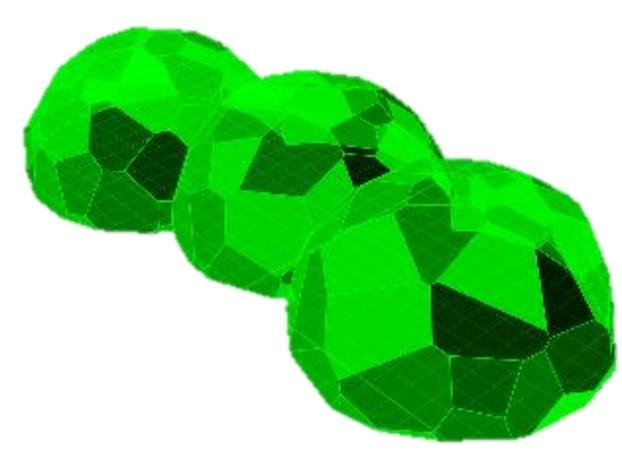

Figura 2: Planificação Kangaroo (Fonte: autores)

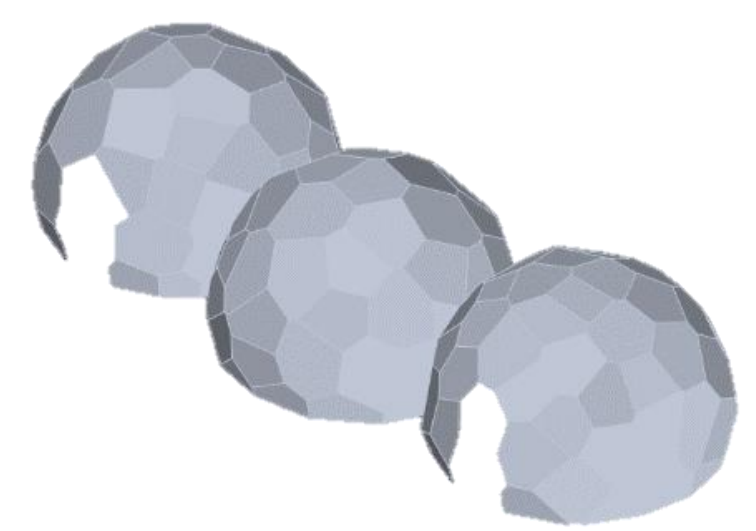

Figura 3: Eliminação de placas para abertura (Fonte: autores) 


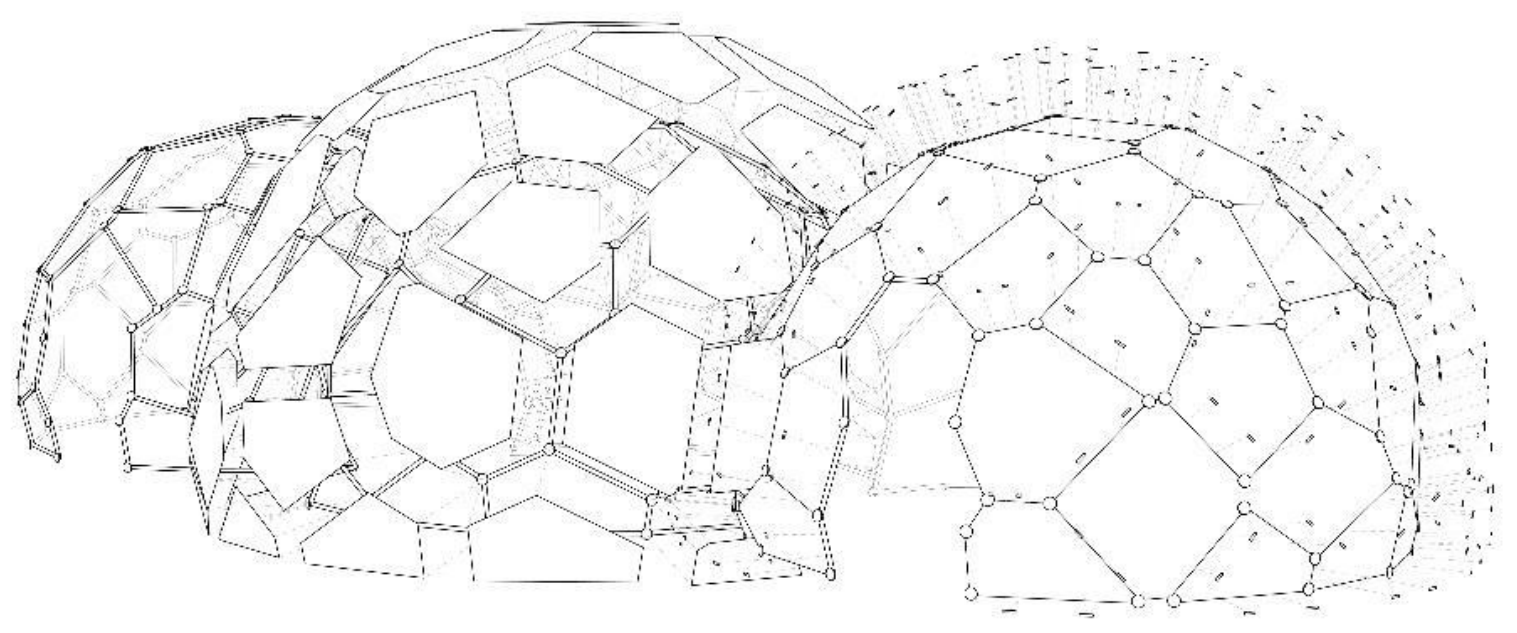

Figura 4: Detalhe dos elementos construtivos (Fonte: autores)

começa de cima para baixo ou de baixo para cima. Quando você se move por todo o ciclo tem que combinar ambas as abordagens." (WALLISSER, 2018, p. 198 a 205). Como resultado, a hierarquia das geometrias aqui fica clara, podendo variar de acordo com as necessidades da próxima etapa.

\section{SEGUNDA ETAPA - SISTEMA GENERATIVO}

Nesta etapa, com o conceito consolidado, o foco é o de gerar um projeto viável e que atenda às necessidades do cliente. Para isso foi fundamental a utilização do software Rhinoceros e seu plug-in de programação visual Grasshopper. O processo de modelagem começou com a parametrização de três semiesferas limitadas pelo volume disponibilizado no evento, com partes que se sobrepunham e com parâmetros que permitiam a alteração do raio, o afastamento das esferas em relação ao chão, a localização de cada esfera, etc.

Para o desenvolvimento da casca foi utilizada a interseção entre as semiesferas com um padrão de voronoi 3d. Isso gerou então um padrão de voronoi curvo, seguindo o formato das três semiesferas. Para o próximo passo, foi necessário fazer a planificação desse padrão de voronoi de forma a obter placas planas que se encaixavam perfeitamente e prontas para o corte à laser. Foi então utilizado o plugin para Grasshopper chamado Kangaroo, que através de um método de relaxamento dinâmico calcula as dimensões necessárias de cada aresta do domo para que todas as células de voronoi ficassem planificadas.

Porém, durante este processo verificou-se que no local em que as esferas se interseccionam as hastes precisam manter o mesmo tamanho e localização de maneira a manter a fluidez da forma e sem perder o padrão de voronoi. O algoritmo foi desenvolvido então de maneira que durante o processo de planificação das células, as arestas das intersecções eram forçadas a se igualar.

Foi partir desta geometria-base que os elementos tridimensionais foram criados. As placas ganharam espessura e as hastes ganharam diâmetro. Foi possível também criar possibilidades de conexões que pudessem ser produzidas através de fabricação digital, como impressão 3D por exemplo.

\section{TERCEIRA ETAPA - FABRICAÇÃO}

A terceira etapa foi a construção do projeto em si. Nesta etapa uma outra empresa foi contratada: a Paleta Stands, localizada na cidade de Joinville em Santa Catarina. Eles foram os responsáveis pela parte de prototipagem e fabricação do pavilhão, o que significou a perda do controle sobre o processo de fabricação que se imaginava durante a fase de programação e consolidação da geometria através do design digital. A empresa possuía toda a documentação e arquivos necessários para a produção do pavilhão utilizando exclusivamente métodos de fabricação digital. No entanto, as instruções passadas permitiam a eles uma grande flexibilidade para resolver o projeto da maneira mais otimizada possível, levando em conta a tecnologia, custos e mão-de-obra disponível.

Ao realizarmos as visitas técnicas para acompanhar o desenvolvimento do projeto, verificou-se que o processo de fabricação havia mesclado uma variedade de métodos. Para o corte das placas de policarbonato alveolar foram usadas máquinas de corte à laser, o que garantiu uma grande precisão e um alto nível no acabamento final.

Já para a produção do esqueleto metálico, foi contratada uma equipe de serralheiros tradicionais, ou seja, que não estavam acostumados a produzir um projeto de tamanha complexidade formal. Foram repassados para eles apenas as dimensões das hastes metálicas e perspectivas com as hastes devidamente etiquetadas. Os serralheiros começaram soldando as peças da base que estavam indicadas com precisão na planta geral, mas para as hastes seguintes eles não possuíam referências espaciais que os guiasse no processo de solda. Dessa forma, foi um imenso trabalho de tentativa e erro, pois conforme as hastes eram soldadas, começava-se a 
verificar que as próximas hastes da lista não batiam exatamente como indicado nos desenhos. Era necessário então serrar as peças anteriores para rearranjá-las de maneira que as seguintes encaixassem nos locais especificados. O projeto só pôde ser compreendido de forma mais clara pelos serralheiros quando mostramos uma maquete física em escala 1:10 em uma das visitas técnicas feitas.

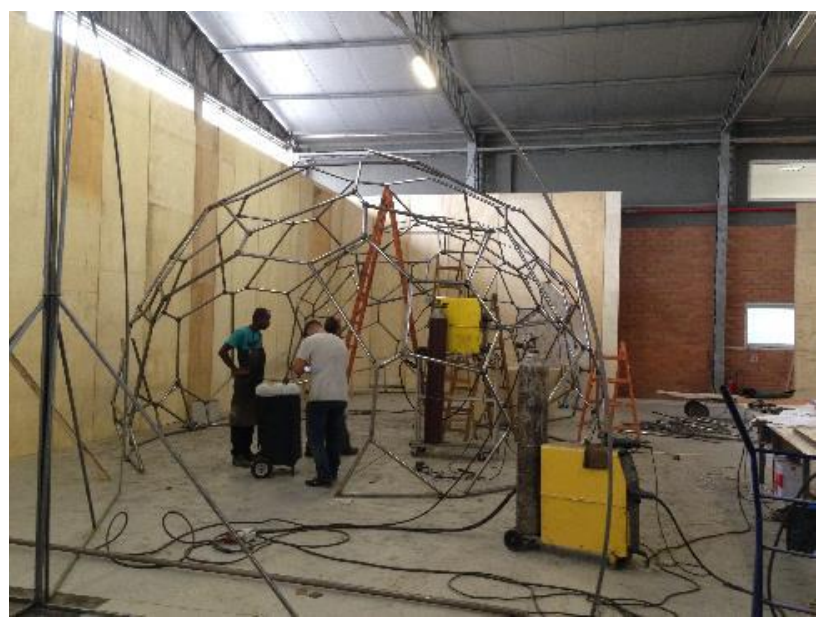

Figura 5: Serralheiros e a maquete (Foto: Daniel Locatelli)

Este processo que se assemelhou à um quebra-cabeças, acabou ocasionando distorções nas células de voronoi que haviam sido planificadas na etapa de projeto. Cada célula apresentou ao final dupla-curvaturas que foram compensadas com a flexibilidade do policarbonato alveolar. Isso acabou gerando reflexos distorcidos na superfície da casca que podem ser notados na Figura 7. Esse resultado estético não foi previsto inicialmente, mas foi absorvido e aceito como sendo um aspecto natural desse tipo de fabricação artesanal.

Além da fabricação por solda gerar irregularidades na superfície da casca, foi necessário segmentar o pavilhão (Figura 6) de maneira que ele pudesse ser transportado em um baú de caminhão com medidas de no máximo
$8,5 \mathrm{~m} \times 2,4 \mathrm{~m} \times 2,5 \mathrm{~m}$ (largura, comprimento e altura respectivamente). Isso fez com que mais algumas pequenas inconsistências surgissem ao longo do processo, mas nada que de fato afetasse o resultado final.

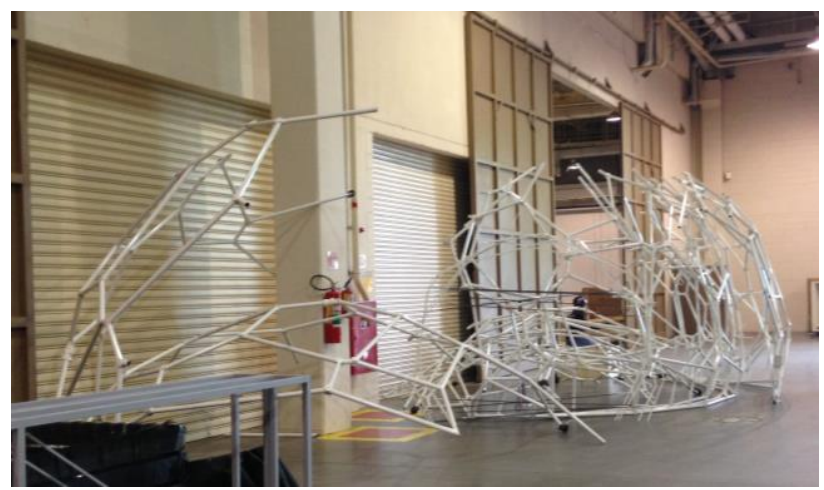

Figura 6: Segmentação para transporte (Foto: Daniel Locatelli)

\section{CONSIDERAÇÕES FINAIS}

Os arquitetos estão presenciando uma mudança radical no método de projeto e fabricação de construções. A dúvida não é mais se a profissão vai ou não aderir a estas novas tecnologias. Mas sim como podemos mesclar e tirar proveito delas sem ignorar os métodos tradicionais disponíveis. Como Gaudí usava maquetes físicas para conversar com seus artesões, neste estudo se fez muito útil essa didática de aproximação do ambiente digital aos serralheiros tradicionais.

Projetar considerando um sistema generativo permitiu neste estudo de caso uma grande flexibilidade na tomada de decisões e nas mudanças das dimensões de cada domo e de cada célula de voronoi com apenas poucos cliques. Isso significa que a documentação se atualizava de forma automática, onde o formato e dimensões de cada placa de policarbonato, o comprimento de cada haste metálica e a localização das bases no piso foram gerados de forma dinâmica, sem retrabalhos manuais.

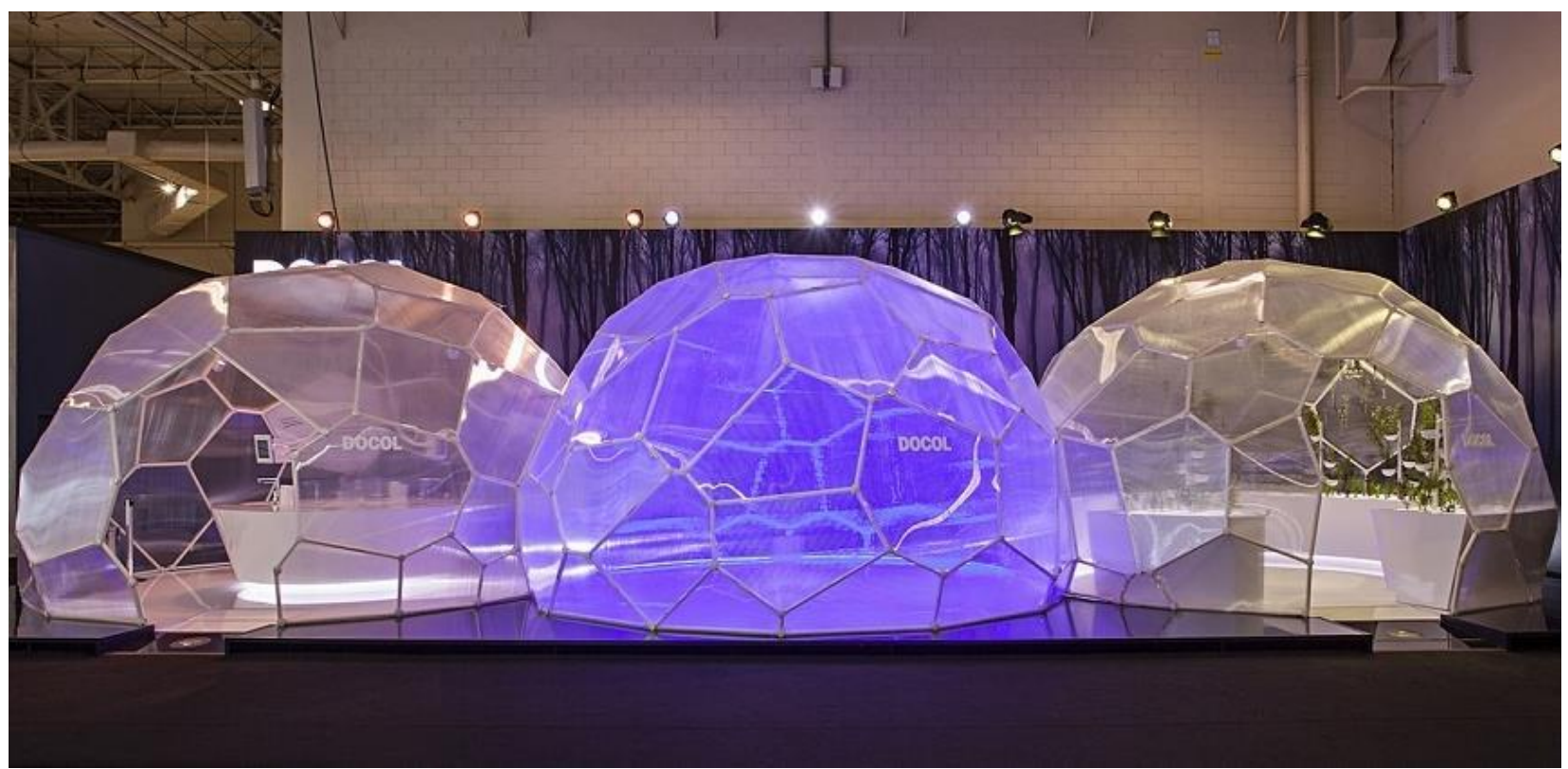

Figura 7: Projeto Finalizado (Foto: Gui Morelli) 
Por fim, evidencia-se a necessidade de que arquitetos busquem soluções inovadoras no modo de se fazer arquitetura, uma vez que essa demanda é o que irá determinar se haverá fornecedores e mão-de-obra com conhecimento necessário para avançar o atual estado da arquitetura no Brasil.

\section{REFERÊNCIAS}

ARAÚJO, A. L. Autômatos celulares: Definição e aplicações na arquitetura. In: CELANI, M. G. C.; SEDREZ, M. (Orgs.). Arquitetura contemporânea e automação: prática e reflexão. São Paulo: ProBooks, 2018. P. 68 a 84.

CARNEIRO, Gabriela. Arquitetura interativa: contextos, fundamentos e design. 2014. Tese (Doutorado em Design e Arquitetura) - Faculdade de Arquitetura e Urbanismo, Universidade de São Paulo, São Paulo, 2014.

CELANI, M. G. C.; SEDREZ, M. (Organizadores). Arquitetura contemporânea e automação: prática e reflexão. São Paulo: ProBooks, 2018.

CELANI, M. G. C.; SEDREZ, M. Arquitetura responsiva. Entrevista com Anne Save de Beaurecueil. In: CELANI, M. G. C.; SEDREZ, M. (Organizadores). Arquitetura contemporânea e automação: prática e reflexão. São Paulo: ProBooks, 2018. p. 174 a 181."

CELANI, Gabriela; SEDREZ, Maycon. Entrevista com Anne Save de Beaurecueil. Entrevista, São Paulo, ano 14, n. 055.01, Vitruvius, jul.

2013 <http://www.vitruvius.com.br/revistas/read/entrevista/14.055/ 4776>.

OXMAN, Rivka (2006) "Theory and Design in the First Digital Age" Design Studies, Vol. 27 No. 3 pp. 229 - 265
PIKER, Daniel. Kangaroo: Form finding with computational physics. Architectural Design, 2013; 83(2); 136-137

ROJAS, Cristobal. "CoBLOgó / SUBdV" 5 Ago. 2017. Download CAD Blocks, Drawings, Details, 3D, PSD Blocks. Disponível em: <https://www.caddownloadweb.com/coblogo-subdv/>. Acesso em 23 Jun. 2018.

SEDREZ, M. e MARTINO, J. A. Sistemas Generativos. In: CELANI, M. G. C.; SEDREZ, M. (Orgs.). Arquitetura contemporânea e automação: prática e reflexão. São Paulo: ProBooks, 2018. P. 55 a 68.

SUBdV. "CoBLOgó / SUBdV" 26 Jun 2017. ArchDaily Brasil. Disponível <https://www.archdaily.com.br/br/874036/coblogo-subdv> ISSN 0719-8906>. Acesso 16 Jun. 2018.

TEDESCHI, A. AAD_Algorithms-Aided Design: Parametric Strategies using Grasshopper, Italy: Le Penseur, 2014.

TRAMONTANO, Marcelo; SOARES, João Paulo. Arquitetura emergente, design paramétricos e o representar através de modelos de informação. V!RUS, São Carlos, n. 8, dez. 2012. Disponível

em: $<$ http://www.nomads.usp.br/virus/virus08/?sec=6\&item=1\&la $\mathrm{ng}=\mathrm{pt}>$. Acesso em: 26 jul. 2016.

TRAMONTANO, Marcelo. Quando pesquisa e ensino se conectam. Design paramétrico, fabricação digital e projeto de arquitetura. Arquitextos, São Paulo, ano 16, n. 190.01, Vitruvius, mar. 2016. Disponível em: <http://www.vitruvius.com.br/revistas/read/arquitextos/16.190 /5988>. Acesso em: 21 jun. 2016. 